This is a revised and longer version of a chapter that will appear

in Pleasure: A History (edited by Lisa Shapiro, Oxford UP)

March 2017, v1.7

\title{
A Contemporary Account of Sensory Pleasure
}

\author{
Murat Aydede \\ Department of Philosophy \\ University of British Columbia
}

What sort of a difference is the difference between having a taste sensation that I enjoy and having a taste sensation to which I am indifferent or having one that I dislike? Here I use the word 'enjoy' in the sense of finding the sensation pleasant. Is the difference a phenomenological one - a difference in the way the sensations feel to me? Is it therefore a difference that I can normally be introspectively aware of? Or does the difference necessarily involve a difference in (some combination of) my desires, preferences, attitudes, inclinations, dispositions, motivations, or drive states, without necessarily making a phenomenological difference - in other words, a difference in one's conative attitudes? Or is it a difference consisting of both - phenomenological and attitudinal? In this essay, I want to explore some of the historically more recent answers to these questions.

After some initial conceptual ground laying and clarifications, I will raise some puzzles about the ordinary understanding of sensory pleasure as a kind of feeling, look into some alternatives, and develop a comprehensive three-level account of sensory pleasure that is simultaneously adverbialist, functionalist, and is also a version of an experientialdesire account.

\section{Target Specification}

We can label the present quest as one that investigates sensory affect, not in the sense that such affective episodes would themselves be sensations (initially we can leave this open), but rather, in the sense of an affective episode that "attaches" to sensations. For, as the opening sentence suggests, affect, positive or negative, seems to modify sensations that are perhaps otherwise neutral, and they may do that, it seems, without themselves being sensations. For convenience, I will concentrate on positive sensory affect, that is, on pleasant sensations, but what will emerge from our discussion can be extended without too much trouble to the negative affect, to unpleasant sensations. So the focus will be on pleasantness - pleasantness of sensations — rather than pleasure per se. However, there is no harm in using 'pleasure' or 'sensory pleasure', as my title does, so long as we keep in 
mind that it is the affective aspect of sensations, their pleasantness, that we mean to be discussing in what follows.

By 'sensation' I mean such mundane and familiar conscious episodes as the way things taste, smell, feel, sound or look. There is, phenomenologically, something it's like to taste or smell a fresh ripe strawberry, a Castelvetrano olive, a freshly cut Meyer lemon, a piece of dark chocolate, or to feel a chilled peach or a golf ball on your fingers, the gentle kiss of your lover on your lips, or to hear the opening of Albinoni's Adagio, or to see the turquoise waters of Bodrum Bay, and so forth. I have in mind here the very building blocks of conscious sensory experiences when we perceive the world around us through our senses, not the sensible properties of the objects that these sensory experiences represent or are responses to. It is important to be clear about this distinction.

So take, for instance, the smell of a freshly cut ripe watermelon. There is something phenomenologically very distinctive about it. But to what does the pronoun 'it' refer, here? The odour particles emanating from the cut watermelon or certain phenomenal elements of your subjective olfactory experience? The former isn't experiential or subjective at all — these particles would be doing their complex dances in front of your nose even if you had a pretty bad head cold. On the other hand, the latter is (usually) how you become conscious of these odour molecules, and for that matter, of the watermelon - by undergoing a complex set of sensations or an experience involving these sensations. This sort of ambiguity (between a subjective sensation and its physical object) is so pervasive that we don't even notice it, perhaps precisely because we have in mind (or even want) the ambiguous meaning in ordinary conversational contexts. The same ambiguity shows up in the use of 'smell', 'taste', 'sound': these may be referring to whatever physically complex properties of objects are responsible for the sensations they produce when we sense them, or they may be referring to the sensations or sensory experiences themselves thus produced - or, even to some sort of interaction effect between the two. But here we cannot afford the ambiguity. Even though in many ordinary contexts it makes sense to talk about how pleasant the watermelon is, or how pleasant the taste or smell of it is (understood as physical sensible features of the watermelon), it seems clear that this sense primarily depends on its making prior sense of talking about how pleasant the experience of it is. It is, then, the sensations, or sensory experiences, produced by environmental objects (including our bodies), that are said to be the primary locus of modification. That is, pleasantness, whatever it is, primarily qualifies (modifies) sensory experiences, not their objects or their objective sensible properties. Put bluntly and in the present context, only sensory experiences are (non-derivatively) pleasant or unpleasant. ${ }^{1}$

\footnotetext{
${ }^{1}$ See Aydede \& Fulkerson (2014) for an elaboration of this distinction in the context of a critique of strong representationalism about perceptual experiences. This view is not universally accepted: there are people who seem to think that affective qualities are as every bit objective as the shapes, sizes, or colours of objects are - see, e.g., Johnston (2005); many naïve realists and strong representationalists are tempted by this sort of view too. But this is a minority view that I criticize elsewhere - see Aydede \& Fulkerson (2014). I will have more to say on this below.
} 
When people use the word 'pleasure' in the plural (e.g., "pleasures of the palate"), it is usually the environmental sources of such experiences that they have in mind.

The phenomenology of sensing is simpler and less cognitively sophisticated than the phenomenology of perceiving. Compare, for instance, just sensing the sensible properties of a lemon (its yellow colour, taste, smell, etc.) and perceptually recognizing it as a lemon. Lemons are perceptible objects of our experiences. But recognition of a lemon as a lemon in perceptual experience is a relatively more sophisticated accomplishment than, say, the recognition of its colour as yellow - not to say anything about the perceptual recognition of a type-writer or eucalyptus tree as such. I think it is relatively uncontroversial that perceptual identification and recognition is at least partly a cognitive and conceptual affair somewhat continuous with perception. It may be an open question whether, for instance, typewriters, locomotives, or pine trees, can be represented in perceptual experiences as such without the aid of our conceptual capabilities. But it is not controversial that some low-level sensible properties of objects, such as their colour, motion, size, shape, and their sounds in typical contexts, their flavour, etc., can be represented in experiences. All perceptual experiences involve sensory elements (sensations) responding to or representing such low-level physical properties of environmental objects or events (sensible properties). ${ }^{2}$

The notion of sensory pleasure I want to concentrate is one that is associated with sensing low-level properties rather than perceiving high-level properties that involves more sophisticated recognitional abilities. Pleasantness can modify any sort of perceptual experience involving recognition that is integrated with one's background knowledge and concerns. For instance, suppose you are a watermelon farmer and tasting one of your watermelons to see whether they are ripening. You may be tired of watermelon taste or you may be too full, or sick, or whatever, but you may still enjoy great pleasure upon tasting this watermelon simply because the way it tastes to you indicates that your watermelons are ripe and you know that it is early in the season. Knowing that you will be able to get them to the market early and make more profit, you find the taste experience very pleasant. The intuitive distinction here is between the way your taste experience is pleasant solely due to its sensory qualities and the way you find your experience pleasant because of what it indicates when combined with your background information and desires. So, by stipulation in this essay, I mean to restrict my discussion of sensory pleasure to the former kind of cases. I don't mean to suggest that the distinction is clearcut. It may be that there is a continuum and these two sorts of cases are at the more clearly opposite ends of it. As long as there are clear cut end-point examples of this continuum, I

\footnotetext{
${ }^{2}$ Roughly, this overlaps extensively with the set of so-called secondary qualities understood objectively. I will assume that secondary qualities are either complex physical properties of objects or the categorical physical basis of objects' dispositions to cause certain range of sensations under certain circumstances. This assumption is not necessary for my purposes but will facilitate the discussion below.
} 
intend to restrict my discussion to the more sensory end rather than the more cognitive (conceptual, higher, intellectual, etc.) end.

\section{Affective phenomenology}

The notion of sensory pleasure articulated so far is an intuitively understood phenomenon familiar in our daily lives. If the articulation so far is intuitively familiar, a few implications I will draw attention to should not be too controversial either. What follows is an exercise in critical phenomenology expanding on this initial intuitive understanding of sensory pleasure.

First, the intuitive notion of sensory pleasure is a mentalistic notion: whatever sensory pleasure turns out to be, it is a mental phenomenon in so far as sensory experiences are mental phenomena. This is not to deny that they may also be physical. Indeed, I am assuming a largely naturalistic/physicalistic metaphysical framework: the account I will develop later is an attempt to understand sensory pleasure in such a naturalistic framework. The point is rather that pleasantness is a mental aspect of our sensory experiences (subjective) rather than a physical aspect of the environmental objects (objective) that such experiences are experiences of. This is important because it follows from this that our epistemic access to the pleasantness of our own experiences is introspective rather than exteroceptive. If and when we correctly judge that a sensory experience we are having is pleasant, this judgment is a piece of introspective knowledge if it is knowledge at all. The intuitive notion of sensory pleasure thus implies that our epistemic access to our own pleasant experiences has the same kind of directness and epistemic authority as whatever direct and authoritative access we have in general to our own experiences. ${ }^{3}$

A second point also seems obvious enough: pleasant sensations are noninstrumentally good to have - and unpleasant experiences such as painful pains or foul smells/tastes are non-instrumentally bad to have. As such, pleasant sensations are intrinsically desirable - desirable as an end in themselves (this doesn't prevent them from also being instrumentally good or desirable or bad and undesirable). This makes pleasant sensations $a$ worthy object of our desires - even though as a matter of fact, due to overriding factors or competing desires, many or most of the time we may rightly decide not to pursue them. So, pleasant sensations are intrinsic (but defeasible ${ }^{4}$ ) motivators, and there are many circumstances our desires and subsequent actions are justified by their intrinsic goodness. Therefore, the pleasantness/unpleasantness of our sensory experiences rationalizes our behavior and thoughts about them: in other words, they make these

\footnotetext{
3 Obviously, this doesn't mean that we are incorrigible about our experiences and their affective aspects. Further, this doesn't imply that our sensations can be pleasant only if we have introspective access to them.

${ }^{4}$ By this, I only mean that even though their value is non-instrumental in the sense specified, their motivational power may be curtailed by the motivational power of other states or considerations. Also, for the purposes of this essay, I won't distinguish between non-instrumental and intrinsic value (for the agent).
} 
thoughts and actions intelligible from the subjective perspective of the experiencer intelligible both to the experiencer herself and to others who try to understand or explain the thoughts and actions of the experiencer. We can put the point of this paragraph by saying that the pleasantness or unpleasantness of sensory experiences provides or constitutes reasons for the experiencers - motivating, rationalizing, and justifying reasons for their thoughts and behavior. ${ }^{5}$

A third point relates to what is said in the opening paragraph: pleasantness or unpleasantness modifies sensations without themselves necessarily being sensations. The term 'sensation' is sometimes used in a very broad way as meaning whatever it is we can discern phenomenologically in our experiences or as a near synonym of 'feeling' meant to capture whatever elements make up one's experiential phenomenology — in contrast to more cognitive phenomena such as judgments, knowledge, beliefs, etc. I am not using 'sensation' in this broad sense, but in the narrow sense meant to mark the phenomenology of exteroceptive sensory access to our extra-mental environment. So if our sensory modalities function to provide us with information about the physical features or magnitudes of our environment (including bodily environment), sensations are those that represent or informationally respond to these features or magnitudes. As said, these are typically low-level features such as colours, sounds, odours, flavours, heat, cold, etc. mostly, whatever (complex) physical features or magnitudes constitute (or are responsible for) so-called secondary qualities. Sensations, in other words, are those for which the question of exteroceptive representation can meaningfully be raised and empirically answered. ${ }^{6}$ Is it part of the intuitive understanding of sensory pleasure as modification of sensations that the pleasantness of a sensation represents or indicates a physical feature or magnitude of an extra-mental object or event somehow related to whatever physical feature the sensation itself indicates? In my terminology, this is the question of whether we intuitively conceive of pleasantness of a sensation as itself being a sensation (in my narrow sense). The answer is clearly no. ${ }^{7}$

\footnotetext{
${ }^{5}$ I will assume a distinction between motivating/rationalizing reasons, on the one hand, and justifying reasons on the other. That I believe my cell phone is in the drawer is a motivating/rationalizing reason for why I open the drawer. But given that my phone is in fact on the kitchen counter, it doesn't provide me with a good reason for my action: it fails to normatively justify my action in virtue of being false. But in the case of intrinsic value of sensory affect, the motivating and justifying aspects don't generally come apart — but see below.

${ }^{6}$ I don't mean to suggest that answering such questions is easy. As we all know, answering the question of, say, what colour sensations represent turns out to be puzzling and difficult. But at least the question is wellposed and empirically well-motivated: we know that there are physical/objective features out there in the environment, for instance, sets of surface spectral reflectances, about which our colour sensations carry information.

${ }^{7}$ Recently, Cutter \& Tye (2011) argued that, notwithstanding our intuitive understanding, sensory affect represents complex higher-order historical/relational properties such as being harmful or beneficial to the organism. This is a radically revisionary philosophical theory that I criticize elsewhere - see Aydede \& Fulkerson (2014).
} 
Thus, if sensations can be pleasant or unpleasant, and if pleasantness or unpleasantness is phenomenologically real, then the phenomenology of our perceptual experiences may be complex being somehow constituted by at least two components: there is the core sensory phenomenology somehow representing or at least informationally responding to the physical features or magnitudes of our extra-mental environment, and there is the affective phenomenology somehow modifying the sensations involved in this sensory phenomenology. We can now see that if sensory affect is a modification of sensation, and is not itself a sensation (in my narrow sense), it cannot exist without the sensation - just as smiles cannot exist without faces, or limps cannot exist without walkings, etc.

Furthermore, we noted above that whatever the nature of sensory affect is, it has intrinsic value. It follows that what is intrinsically good or bad is, de facto, the whole complex: it is the perceptual experience consisting of affect and sensation that is intrinsically good or bad, and thus inherently motivating and justifying. The upshot is that being motivated by a pleasant sensation, say, the pleasant taste sensation produced by taking a bite from a slice of watermelon, is ipso facto being motivated by the taste of the watermelon, thus, consequently, being motivated, for instance, to eat more watermelon. Insofar as sensations present us with (physical) sensible features of extra-mental objects, the pleasantness or unpleasantness of these sensations is therefore motivationally directed upon these features and whatever objects or events these features are features of. This is why we also call these features themselves pleasant or unpleasant, not just their sensations.

I mentioned the ambiguity above that exists about the reference of 'taste', 'smell', 'feel', and the like. When we talk about the taste or smell of watermelon, it makes no practical difference whether we are referring to the objective features of the watermelon causally responsible for their sensations or the sensations themselves so produced, or even to some sort of interaction effect between the two and our consummatory activities. There is an obvious sense in which sensations are diaphanous: we sense the extra-mental world right through them. ${ }^{8}$ But certain aspects of the sensorially manifest world can be affectively significant precisely because the sensations that make this world manifest to us can be affectively modified.

The third point can be summarized thus. Although the sensory affect "attaches" primarily to sensations by modifying them, there is an obvious function affect thereby performs: it makes the objects of sensations (i.e., whatever physical features or magnitudes our sensations detect) motivationally salient - as not only the de facto objects of our ongoing experiential (non-conceptual) pro- or con-attitudes, but also as objects worthy of

\footnotetext{
${ }^{8}$ We can certainly introspectively report the presence of sensations and attempt to introspectively characterize what they are like, but we do not sense our sensations or their affective aspects in any way like the way we sense the extra-mental world. We sense the extra-mental world with them and find the aspects of this world affectively significant through the affect modifying these sensations. How introspection of experiences works is a huge topic I cannot undertake here. But see Aydede \& Güzeldere (2005), and my (forthcoming) for extensive discussion.
} 
our cognitive (conceptually structured) pro- or con-attitudes (our ordinary desires or wants, as propositional attitudes, to pursue or avoid).

I take the foregoing to be supported by critical reflection on the phenomenology of sensory pleasure (and sensory affect in general). Any theory of sensory pleasure should therefore aspire to do justice to this phenomenology. My description of this phenomenological framework isn't meant to be a non-tendentious one. As we will see, there are aspects of it that are questioned and indeed sometimes outright rejected by philosophical theories with different ideological alliances and agendas. I agree that none of the foregoing is non-negotiable in principle. But my hope is that the above framework gives us the right cleaned-up version of the intuitive target phenomenon to be explained or at least a version largely agreed upon by most theorists working in the field. Theories that can accommodate this framework more completely should therefore be preferred to theories that are forced to reject essential elements of it. My three-level account I will develop below is superior to all other theories in this respect.

\section{Puzzles}

There have been various puzzles about sensory pleasure that have plagued philosophical (as well as scientific) theories of pleasure. I will highlight what I take to be the three most challenging puzzles in this section.

\section{Heterogeneity}

If the above phenomenological description is largely correct, one might wonder what else or what more needs to be said in order to develop a philosophical understanding of sensory pleasure. ${ }^{9}$ According to the framework above, sensory pleasure is a kind of feeling in the broad sense in which any phenomenal element in one's experience is a feeling - it is a phenomenological occurrence generally accessible to one's introspection. So the intuitive framework is realist about the phenomenology of sensory pleasure. This entails that there is some common phenomenology to all sensory pleasures. But right herein seems to lie one of the puzzles about sensory pleasure. The moment we start asking what this common element is - common to all pleasant sensations in all their rich variations and difference - we seem to draw a blank. If there is a common phenomenological element to all

\footnotetext{
${ }^{9}$ To be sure, there are serious philosophical questions about the metaphysics of phenomenology and its place in nature. An explanatory gap is said to exist between phenomenal consciousness and its physical realizers (Levine 1983, 1993). But these are general questions that concern any kind of conscious phenomenology, not just affective phenomenology. So even we have the full story about the brain circuitry underlying sensory pleasure, an explanatory gap is likely to remain unclosed. Philosophical theories of sensory pleasure (or, affect, in general) have been developed with more particular problems in mind peculiar to affect. But see below. See Aydede \& Güzeldere (2005) for a lengthy physicalist response to the challenge posed by explanatory gap.
} 
pleasant sensations, it seems elusive. All we can say seems something like: all pleasant sensations feel good.

Think of the examples I gave when I was talking about sensations above: the sensations I have when I taste or smell a fresh ripe strawberry, a Castelvetrano olive, a freshly cut Mission fig or a Meyer lemon, a piece of dark chocolate, or when I feel a chilled peach or a golf ball on my fingers, the gentle kiss of my lover on my lips, or when I hear the opening of Albinoni's Adagio, or when I see the turquoise waters of Bodrum Bay, and many others as diverse as these - I like them all. I find them pleasant. Yes, they all feel good, but I am at a loss when I reflect on what phenomenological element unites them all as pleasant. If there is one, I can't seem to locate it in introspection.

In the literature, this difficulty is known as the "heterogeneity problem" for the socalled felt-quality views of sensory pleasure. These are views that endorse the intuitive framework developed above and claim that sensory pleasure is a kind of felt phenomenal quality common to all pleasant sensations. There are basically two discernable variants of felt-quality views in the literature: ${ }^{10}$ those who take sensory pleasure to be (i) a distinctive feeling, ${ }^{11}$ or (ii) a hedonic tone. ${ }^{12}$ The former variant is not popular, but the latter is. The felt-quality views, building on the intuitive framework, insist that the pleasantness of sensations has a phenomenological reality that has a detectable occurrence in our sensory experiences. Very roughly, the distinctive feeling views take this reality to be a phenomenologically uniform occurrence across all pleasant experiences, whereas the hedonic tone views allow for variations in the phenomenological character of this occurrence without losing its identity. Although the hedonic tone views are meant to be more nuanced and subtle in this regard, they are somewhat more difficult to grasp since it is not clear how to understand this variable but somewhat identifiable phenomenal character (hedonic tone). I will get back to this below and offer a framework in which we can make better sense of the notion of hedonic tone.

\section{Motivation and intrinsic value}

It is also part of the intuitive framework that pleasant sensations are inherently motivating and intrinsically good - and surely these two features are intimately related. Puzzles arise, however, when we try to understand how all this could be so. If pleasantness is a kind of feeling somehow modifying a sensation, it is somewhat mysterious that it can be

\footnotetext{
${ }^{10}$ See Feldman (2001) for the terminology and very helpful discussion of the relevant categorizations.

${ }^{11}$ Early G. E. Moore (1903/1993: 12) is probably the most explicit statement of the view. But also see Brink (1989: 221): "the one and only intrinsic good is pleasure, which is understood as a simple, qualitative mental state." A more recent defense is Bramble (2011: 2): “... for an experience to be pleasant (or unpleasant) is just for it to involve or contain a distinctive kind of feeling, one we might call 'the feeling of pleasure itself', or simply 'the pleasant feeling' (or, in the case of unpleasant experiences, 'the unpleasant feeling')." See also Sprigge (2000).

${ }^{12}$ See, among others, Broad (1930), Duncker (1941), Kagan (1992), Crisp (2006), Smuts (2011), and Labukt (2012).
} 
the kind of thing that can inherently motivate or can be intrinsically good. We know that pleasantness is motivating and good, but we don't know how it could be so if it is a kind of feeling that somehow "attaches" to sensations. ${ }^{13}$

There are several issues here that we need to get clear about. First, start with motivation. Pleasant sensations are inherently motivating. Inherently, because it seems that, in order for them to motivate, the experiencer need not have any further motivating beliefs and desires. It appears that a pleasant sensation all by itself can motivate. It seems mysterious how a mere feeling can have such a power.

Secondly, what is it that pleasant sensations are said to inherently motivate? It is notoriously difficult to answer this question in an abstract and completely general way. Intuitively, we would like to say something like: they (defeasibly ${ }^{14}$ ) motivate behavior intended to do whatever it is that would sustain undergoing the sensation as long as it remains pleasant. ${ }^{15}$ This would make the pleasant sensation (a mental state) the target of intention - thus, the target or the end-state that the behaviour is aimed to bring about. But this is problematic. Motivated behaviour is not merely caused behaviour. Motivation is intentional, so is motivated behaviour - it is behavior performed with an end in mind (however simple or complex, frivolous or serious, misguided or smart this may be). That is why understanding the motivations of an agent behaving in a certain way can make the agent's behaviour intelligible by identifying the reasons for which the agent behaves the way she does. These reasons may be good or bad, justified or unjustified, based on correct or incorrect information or reasoning. But they will make us understand why the agent does what she does. On one way of looking at the target of motivation, this seems to require that the agent be capable of perceiving or thinking of (in general, being in an intentional state $a b o u t$ ) the object or state of affair that she aims for. The end state for which the agent is motivated needs to be thought of by the agent in some way or other. So, even if we put aside our conception of our own motivations, there are animals and young children who obviously can experience pleasant sensations and be motivated by them without having the capability of even thinking of their own sensations - let alone forming intentions about them. So, sensation-directed intentional behaviour cannot always be what pleasant sensations motivate for all that are capable of experiencing pleasant sensations.

Perhaps, it is more plausible to say that the behavior is intended to "consume" whatever object or a physical feature of the object that happens to be the causal source of our pleasant sensation. This would make the "consummatory" behaviour or activity itself (e.g., the act of eating, smelling, feeling, hearing, etc., or their proper objects) the target of

\footnotetext{
${ }^{13}$ Cf. Findlay (1961: 176ff) for worries of similar kind.

14 The kind of motivation under discussion is always defeasible motivation: it can always be overridden with other stronger motivating factors. So I will leave this aside.

${ }^{15}$ A parallel claim can be made for unpleasant sensations such as pain: they (defeasibly) motivate behavior intended to do whatever it is that would stop undergoing the sensation as long as it is unpleasant. As said, although the focus is on sensory pleasure, the discussion and analysis can be extended to all sensory affect, positive and negative.
} 
intention and the end-state aimed. Unlike the former proposal, this is behavior that is extra-mentally directed - roughly, world-directed. It doesn't require the capability of forming intentions about one's sensations, or one's mental states in general. So it is less demanding in this regard.

But is it really more plausible to say that what gets motivated by pleasant sensations is always and exclusively the consummatory behavior - world-directed behavior? This may be true for animals and most young children, perhaps, even for most of us most of the time, but doesn't seem to generalize easily to all cases. When I take a bite from this piece of watermelon, my primary reason may be that I feel hungry (and thus may be aware that a bodily need is to be satisfied). But if you ask me why I took a bite from the watermelon rather than this piece of pineapple, all else being equal, the answer would have to change to something like "because I like watermelon better than pineapple". This may just be another way of saying "the taste of watermelon is more pleasant to me than the taste of pineapple" where 'taste' refers to the taste sensation. And this may be the end of the matter in the sense that there may be no further end to which my having this pleasant sensation (as opposed to that one) is a means. This brings us to sensory pleasure itself being an intrinsic good in the sense that it is an end in itself, something that is not only desired but desirable non-instrumentally — all else being equal. Furthermore, the sensation by being pleasant is generally manifest to me as intrinsically desirable. ${ }^{16}$ As such, it will motivate me to sustain the sensation qua pleasant. This is sensation-directed behaviour, not merely world-directed behaviour.

Thus, sensory pleasure is Janus-faced: it has a motivational face looking both outward and inward. A pleasant sensation of an object motivates both object-directed behaviour and sensation-directed behaviour. It does the former because sensations themselves are outward looking - they are sensations of worldly (extra-mental) objects or events, and are normally diaphanous to their owners, and are generally caused or sustained by the owners' worldly behaviour. It does the latter because on reflection we can grasp the intrinsic goodness of sensory pleasure - that is, we can aim/intend to have pleasant sensations as ends in themselves and act accordingly. This requires that we can have thoughts and desires about our own sensations and their pleasantness. It turns out that it is practically impossible to act to bring about sensory pleasure without bringing about the sensation, and impossible to bring about the sensation without engaging in the relevant consummatory behaviour. If you think about it, this arrangement is a brilliant design feature of our affective/perceptual systems.

But it is puzzling how pleasantness as a kind of feeling that "attaches" to sensations can do all of this. Take the sensation produced upon feeling a peach with your fingers. To most, this is a sensation that is neither pleasant nor unpleasant - it seems affectively

\footnotetext{
${ }^{16}$ Again, all else being equal. Most of the time all else may not be equal. Remember, we are operating under the assumption that all such desires are defeasible. Goldstein (1980) argues that desiring pleasure over pain is a matter of rationally grasping what is normatively evident. I agree with him on this point.
} 
neutral. But to a few, it is an intensely unpleasant feeling — and reliably so. To some, it is a pleasant feeling - I, for one, like feeling the velvety texture of peaches. So we have a tactile feeling indicating a certain kind of texture of a surface that seems, at the core, affectively neutral. What do we need to add to this feeling (sensation) to turn it into a pleasant or unpleasant one understood as inherently motivating and intrinsically good/bad? Another kind of feeling? Saying yes is puzzling, saying no is puzzling. We draw a blank but we want to understand.

\section{Opposite valences}

A third puzzle is about how feelings can have opposites. A sensation can be pleasant or unpleasant. The intuitive framework conceives of pleasantness and unpleasantness as kinds of feeling modifying otherwise affectively neutral sensations to different degrees. This seems to imply that feelings can be opposites in whatever sense the pleasantness and unpleasantness are opposites. But how mere feelings could have opposites seems mysterious.

\section{Contemporary accounts}

So we need good accounts of sensory pleasure that will help us make better sense of the intuitive framework about sensory pleasure by addressing the important features, difficulties, and puzzles involved in this framework.

In the value theory tradition, the main competitor to the felt-quality views has been the collection of views that treat sensory affect as a kind of pro-attitude towards a given sensation said to be pleasant. The nature of this attitude varies from philosopher to philosopher, but the main theme has been that this is a conative pro-attitude such as wanting, desiring, liking, etc. Because of this, this class of views is sometimes called "attitudinal views". ${ }^{17}$ Here is a recent statement of one of the best worked-out accounts of this kind of view given by Heathwood (2007: 32):

\footnotetext{
${ }^{17}$ Here the list is long. Sidgwick (1907) may have started things going, but things are complicated - he used 'desirable' rather than 'desired.' See Alston (1968), Davis (1981, 1982), Brandt (1979), Feldman (1997, 2004), Heathwood (2007), among others, for defenses of attitudinal theories. Parfit (2011) and Brady (2013) develop the attitudinal theory in terms of liking (or disliking) a sensation, where this hedonic attitude is taken to be different from desiring in that it is not meant to be responsive to reasons (see my 2014 for a critical evaluation). Robinson (2006) gives an account of sensory pleasure that is hard to classify but seems closer to the attitudinal theories as he takes the pleasantness to essentially involve intentional and evaluative directedness toward sensations. See also Armstrong (1962), Pitcher (1970), Tye (1995), Hall (1989), Kahane (2009) for proposals that can be categorized as attitudinal.
} 


\section{(DESIRE-THEORY)}

a sensation $S$, occurring at time $t$, is a sensory pleasure at $t$ if, and only if, the subject of $S$ desires, intrinsically and de re, at $t$, of $S$, that it be occurring at $t$.

Attitudinal theories are developed, more or less, as reactions to the difficulties and puzzles inherent in the above intuitive framework and the felt-quality views that attempt to turn this framework into a more systematic account of sensory pleasure. Indeed, the heterogeneity worry is explicit in most attitudinal theorists. For instance, Heathwood writes: “... the phenomenology just doesn't bear it out — there doesn't seem to be any one feeling (or even "hedonic tone") common to all occasions on which we experience pleasure or enjoyment" (2007: 26).

If anything like the desire-theory is true, we can see how the puzzles raised above can be resolved. The heterogeneity problem presumably is no longer a problem since what unites all the qualitatively different pleasant sensations is not the presence of a unique kind of mental quality or feeling, which has proved to be elusive, but is rather a conative attitude toward those sensations: they are all desired in the way specified.

The second puzzle about motivation and intrinsic value can be resolved too. It is generally the accepted view among philosophers that an explanation of motivation in terms of desires (or similar conative states) is not problematic. In fact, this view is so prevalent that it may be the responsible factor for the generation of the puzzle in the first place: how to make sense of the motivational power of a mental state in the absence of any sort of desire, or a desire-like conative state, somewhere in the vicinity? A mere feeling seems powerless to move. According to the desire-theory, pleasant sensations are inherently motivating because they are made up of desires: at bottom, a pleasant sensation is a desired sensation. So a pleasant sensation doesn't need any further beliefs and desires to motivate - it is motivating all by itself.

Moreover, pleasant sensations motivate sensation-directed behavior - behavior gauged to sustain the sensation as its ultimate aim. But, as we have seen, practically this requires outward "consummatory" behaviour directed to sustain the physical stimulus causing the sensation. So, according to the desire-theory, pleasant sensations are both sensation-directed and world-directed in their motivational structure.

As to why pleasant sensations are intrinsically good and desirable: that is because they are satisfied desires - desiring of a sensation that is simultaneously satisfied by the presence of the very same sensation. ${ }^{18}$ This relies on the strong intuition that, all else being equal, satisfaction of a desire is intrinsically good for the agent. Properly understood, very few people would reject this intuition.

The third puzzle is also easily solved. A sensation can be pleasant or unpleasant. The oppositeness is simply a reflection of different attitudes. This can be handled in either

${ }^{18}$ See, for instance, Heathwood $(2006,2011)$ 
of two ways by saying that an unpleasant sensation is one that is not desired (unwanted, disliked, etc.), or by saying that its cessation is desired (wanted, liked, etc.). Either way, there doesn't seem to be a deep mystery here.

But the attitudinal theories have their own problems. Here I will only be able to touch upon intuitively the most general and fundamental problems. ${ }^{19}$ The theory is irrealist about the phenomenology of sensory pleasure. It denies the existence of any phenomenological element common to all pleasant sensations. Instead it proposes that what is common is a mental attitude: they are all desired in a certain manner. For this to be a successful response to the heterogeneity problem, the desiring (or, whatever attitude is proposed) needs to contribute no phenomenology to sensations that are said to be pleasant, so that there is no phenomenological difference among an affectively neutral sensation, an unpleasant sensation, and a pleasant sensation, even when the phenomenology of the sensation is kept the same. For instance, the difference between a smell sensation that you find very pleasant on a given occasion and the same sensation you find unpleasant on another occasion is not a difference you can tell by relying on how the two feel. The attitudinal theorist can certainly grant that we are unreflectively prepared to say that the former feels good and the latter bad. But the theorist needs to insist that this is shorthand for some way of differentiating between the two that is not based on how the two experiences feel. This is counterintuitive and implausible, especially in the absence of a credible answer, on the part of the attitudinal theorist, to "how else to tell them part?"

Note further that the biconditional in the formulation of the desire-theory above is meant by Heathwood to be not just material extensional equivalence but to be necessary equivalence that is known a priori. Heathwood and many other attitudinal theorists advance their accounts on the basis of conceptual analysis and the resulting theses are claimed to be conceptually true. This is even taken to be a superiority of their account over the felt-quality views because conceptual reduction is said to be theoretically illuminating: it advances our understanding by revealing the deep conceptual/metaphysical nature of sensory pleasure (see Heathwood 2011).

But the success of this strategy depends on whether the key notions in the analysans are better understood than the analysandum. Like many other attitudinal theorists, however, Heathwood is unhelpful in his characterization of 'desire' as his favorite proattitude to which sensory pleasure is to be reduced:

To desire something is simply to favor it, to be for it, to be "into" it. Metaphorically speaking, it is to give the thing a mental "thumbs up." I assume that we can take this single attitude towards things in the past, present, and future, towards things true and things false, and towards things we believe and things we disbelieve. For we can certainly favor, or be for, or give a thumbs-up to, anything

\footnotetext{
${ }^{19}$ See my (2014) for a more extensive criticism.
} 
we can conceive, whether past, present, or future, whether true or false, and whether we know it to be true. And this favoring is all I mean by 'desire'. That is the notion that will play a role in the reduction of sensory pleasure to desire to be discussed here. (Heathwood 2007: 25)

So all we have in the way of a proper understanding of the key notion in the analyzans to desire something - is "to favor it, to be for it, to be "into" it", and a metaphor, a "mental thumbs-up". It is simply not plausible that such an underspecified and open-ended notion can do the heavy-lifting in providing us a better and deeper understanding of what sensory pleasure is, especially when this is simultaneously meant to be the denial of any affective phenomenology. Whatever initial plausibility the thesis might have, it seems to draw it from the mundane (but still questionable) plausibility of the biconditional read as an extensional equivalence (even a nomological equivalence). But this should not be mistaken for conceptual/metaphysical constitution.

However, the really fundamental flaw of all attitudinal theories when proposed as conceptual reduction is that they have to take the pro-attitude involved as an intentional attitude. For we don't have a non-intentional notion of a pro-attitude to serve as the basis for conceptual reduction. Heathwood is kind enough to be explicit about this: the notion of desire he has in mind is one that can target anything we can conceive or think of past/present/future, true/false, imaginary/actual, etc.

The intentionality of desire and other pro-attitudes that are supposed to reduce sensory pleasure entails that any creature that is capable of having pleasant sensations can form an intentional state about its own sensations. This entails that the creature be capable of occupying states that refer to its own sensations and that can attribute (predicate) a feature to them thus referred — be it in indicative mood or conative mood. Again, Heathwood is explicit about this in his formulation above: the subject ought to be able to make a de re reference to its own sensation and make a predication. ${ }^{20}$ So it turns out that, according to attitudinal views, in order for a creature to be able to undergo pleasant sensations, the creature needs to be capable of forming thoughts about its own sensations, which is to say, it needs to be able to introspect its sensations. This is simply not credible.

There is also the much discussed "Euthyphro problem" for attitudinal theories. Focusing on the desire-theory, we can put the problem by asking a question: If a sensation is pleasant for a subject and the subject desires it (intrinsically, contemporaneously, de re, etc.), is the sensation pleasant because the subject desires it, or does the subject desire the sensation because it is pleasant? The desire-theorist is committed to an affirmative answer to the former question. ${ }^{21}$ The 'because' here need not be interpreted as merely asking a causal question (asking for causal explanation), but rather as inquiring into the reasons

\footnotetext{
${ }^{20}$ Never mind that the content of the de re desire, according to Heathwood's formulation, seems merely quantificational rather than predicational. See my (2014) for more criticism.

${ }^{21}$ As readily acknowledged by Heathwood himself (2007: 38-40).
} 
why the experiencer desires the sensation that she does. The difficulty here is that we would like to say intuitively that one desires a sensation for the reason that the sensation is pleasant. But the desire-theorist by taking the converse route is precluded from saying that one desires a sensation for that reason. In fact, the desire-theorist is stuck with the fact that she cannot say that the sensation is desired for any reason at all. For suppose it is said that a sensation is desired for a reason other than just having the sensation itself. This would make the desire instrumental. Hence, the attitudinal theories cannot explain why one desires a sensation on the occasion that the sensation is pleasant. This doesn't of course preclude the desire-theorist from saying that pleasant sensations provide good reasons for desiring them. This just means that desired sensations provide good reasons for us to desire them - i.e., to desire the desired sensations. This is plausible only if we are using the term 'desire' quite differently in its two occurrences - see below.

Attitudinal theories of sensory pleasure have serious problems. They were meant to advance our understanding of what sensory pleasures are and go beyond what felt-quality views can offer. They don't do that. In fact, they make things even worse by first denying that sensory pleasure is a matter of phenomenology and then offering an account that requires sensations to be the intentional target of a pro-attitude for no reason at all just to turn them into pleasant ones.

Attitudinal and felt-quality views have been the most popular and dominant attempts to give philosophical accounts of sensory pleasure in the last 100 years or so. Various core elements of these views had appeared before in the history of philosophy, of course. But surprisingly there hasn't been any other sustained attempt in recent years. In particular, philosophy of mind doesn't have much to offer about sensory pleasure. Recent years have seen a lively debate and a plethora of theories on pain and in particular on the affective aspect of pains. ${ }^{22}$ But apart from some brief remarks here and there, no systematic attempt has been made to address the nature of sensory pleasure and the puzzles it gives rise to. ${ }^{23}$

What follows is a proposal that will combine elements from felt-quality and attitudinal views but will be markedly different from them. It will also solve the puzzles in a way that will remain faithful to the phenomenology and the intuitive understanding of

\footnotetext{
${ }^{22}$ See, for instance, Cutter \& Tye (2011), Martínez (2011), O’Sullivan \& Schroer (2012), Bain (2013), Klein (forthcoming), Aydede \& Fulkerson (forthcoming).

${ }^{23}$ See note 37 below for some discussion of recent developments in the philosophy of mind regarding the affective aspect of pain experiences. Subsequent to Ryle's attack on mental episodes as inner causes of behaviour and his attack on pleasure as an inner feeling episode, the 1950's through mid 1970's experienced a lively debate whether pleasure was more dispositional than episodic as Ryle claimed. This debate in some ways parallels the worries that split the felt-quality and attitudinal theorists. See my (2000) for a critical survey of this debate. See also Wolfsdorf (2013, Chapter 9) that contains a very helpful critical survey of this debate and related others. The work of Tim Schroeder $(2001,2004)$ is an exception to the claim made in the main text: although his work tends to focus on desire, he has developed a scientifically informed account of pleasure that is generally friendly to the view to be presented below. See also Katz $(1986,2005)$, whose views, to the extent I can pin them down, are congenial.
} 
sensory pleasure. It is in fact three proposals - each proposal pitching the account of sensory pleasure at a different level. Thus, the account to be proposed may be called, depending on the level, an adverbialist, a functionalist, or an experiential-desire account. The adverbialist proposal offers a model or framework for a proper conceptualization of the complexity and structure of the qualitative phenomenology of affective/sensory experiences. The functionalist proposal then offers an account about the metaphysical realization of this phenomenology. When these two levels are considered simultaneously, another descriptive level between the two becomes intuitively compelling: this is the view according to which a pleasant sensation is an experiential desire and belief directed upon the same worldly stimulus.

\section{A three-level account of sensory pleasure}

One of the interesting things about the debate between the defenders of felt-quality and attitudinal views is that both camps claim that introspective evidence favors their side. It is notoriously difficult to settle a debate of this sort. On the one hand, following common sense, we would like to say that sensory pleasure is a kind of feeling. But feelings are paradigmatic phenomenal episodes: they are conscious phenomenological occurrences. On the other hand, when we try to introspectively spot a phenomenological commonality to all the different kinds of pleasant sensations, we seem to come up empty handed. What to do?

\section{Adverbialism}

Most hedonic tone versions of the felt-quality views have been developed with this problem in mind - the heterogeneity of pleasant sensations that still feel good. Although there seems to be serious confusion about how exactly to interpret these theories, the intention has always been that the affective tone of an experience isn't like the phenomenology of sensory qualities (qualia, sensations), but is to be understood rather like sensory qualities "affectively toned" — the intuition being that this affective tone is a higher-order property (or a dimension) of first-order sensory qualities of experiences (or, a property of their instantiation). Thus affect has been thought by the hedonic tone theorists to have a peculiar phenomenology somehow piggybacking on the ground-level phenomenology of the sensory qualities. But hedonic tone is a phenomenological occurrence, and in this sense, a feeling. How to make sense of this sort of intuition? How should we conceptualize the phenomenological structure of pleasant sensations? My first proposal is: adverbially.

We need to distinguish the phenomenology of sensations from the phenomenology of pleasantness that modifies/qualifies these sensations. Sensations are, in my narrow sense, the fundamental qualities of our perceptual experiences that register a range of complex physical features or magnitudes of objects that we encounter when we sense our environment. Psychophysics has been in the business of cataloging what these 
features/magnitudes are and what the corresponding sensory qualities are that register them. It turns out that the sensations proper to each sensory modality have a rich and complex systematicity to them that we can represent as multi-dimensional quality spaces. The best known example of this is the three dimensional colour solid consisting of brightness, hue, and saturation. Every shade of any humanly visible colour quality is a point in this space. The quality space or spaces of other sensory modalities are not as well known or understood - partly because the number of dimensions involved is controversial and they are very difficult to study empirically. ${ }^{24}$ But progress is being made, and there is not much controversy about the existence of these quality spaces.

Can affect be added as a separate dimension to any given quality space that characterizes a given sensory modality? The answer is yes and no. No, because pleasantness of a given sensation as a phenomenological occurrence doesn't register an objective feature or magnitude of the stimulus in the way the sensation itself does (in our narrow sense) - a given sensation can be pleasant or unpleasant or affectively neutral without this variation necessarily corresponding to any physical variation in the stimulus. But also, yes, in a way, because affect is a way a stimulus is presented to us in sensing it: whatever sensations we may be undergoing registering physical features of a stimulus, these sensations occur modified with affect, thus presenting the stimulus of the sensation under an "affective light". Thus the instantiation of sensory qualities is modified in an affective dimension registering the reaction of the subject to the perceived object (stimulus, or the physical features of this stimulus). I want to model this structure by saying that affect (pleasantness) is an adverbial modification of the instantiation of sensations. An analogy may be helpful here: think of dancing $(\approx$ perceptual experience) different dances (tango, waltz, swing, etc. $\approx$ different sensory qualities, sensations) fast, moderately, or slowly ( $\approx$ affective modification of sensory qualities as pleasant, neutral, unpleasant, etc.). Similarly, when I find the taste of the watermelon pleasant, I am undergoing a taste sensation registering certain physical features of the piece in my mouth, but at the same time the sensation is being affectively/hedonically "toned" making the object of the sensation (this piece of watermelon in my mouth) affectively, thus motivationally, salient to me. This toning is the affective adverbial modification of the relevant sensory qualities. Ryle was onto something when he said, in a similar context discussing pleasure, "The enjoyment of a walk is not a concomitant, e.g., an introspectable effect of the walking, such that there might be two histories, one the history of the walk, the other the history of its agreeableness to the walker" (1954: 138). My proposal is, in a certain sense, to internalize Ryle's behavioral adverbialism, making it a matter of how the sensory qualities with their different and heterogeneous phenomenology are instantiated in conscious experience. This is the affective dimension of experiences with a continuum

\footnotetext{
${ }^{24}$ See Clark (1996) for an overview of psychophysical studies of quality spaces of various sensory modalities and the practical difficulties involved in conducting the experiments (multidimensional scaling experiments) required to map out these spaces.
} 
ranging from positive, passing through neutral, to negative hedonic tone. ${ }^{25}$ Likewise, in my story, there are no two separate histories because there are no two separate phenomenological existences. The realization of one is the adverbial realization of the other.

This model explains why, when we try to "isolate" a quality or a feeling peculiar to sensory pleasure, we always seem to end up with the sensory qualities themselves directing our attention to the external objects and their sensible properties they present. In fact, that's why we also attribute affective qualities (like pleasantness or unpleasantness) to the (physical) objects of experiences. ${ }^{26}$ Try to isolate the fastness of a fast waltz or a fast tango, you can't do it without paying close attention to the waltz or the tango itself. Nevertheless, the "fastness" or "slowness" common to the different token dances can be discerned. In fact, some dance types can themselves be classified as fast or slow - these might perhaps correspond to relatively hard-wired affective responses to certain kinds of sensations (e.g., sweet tastes). Just as the fastness or slowness of dances can be recognized across different types of dances, the pleasantness or unpleasantness common to various otherwise quite different sensations is detectable, indeed introspectively available. ${ }^{27}$

The alleged difficulty of spotting a phenomenological quality common to all pleasant sensations is due to a faulty model of what it is to introspect phenomenological elements of experiences and what it is to be such a phenomenological element. The critics of hedonic tone theories have in mind the phenomenology of sensations and they don't pay much attention to how the hedonic tone theorists want to explain the peculiarities of affective phenomenology. The adverbialist model offers a better framework for understanding affective phenomenology in line with hedonic tone views. Just as the tempo of various dances can be discerned as, say, fast, the pleasantness of various quite different sensations can be introspectively discerned as a higher-order affective dimension ("hedonic tone") of the sensation, but at the same time, what is being discerned is clearly a phenomenal element of our sensory experiences: it is a modification of sensations - it is a way sensations are instantiated in our experiential consciousness. Thus, the adverbialist model about how to understand the phenomenological structure of sensory pleasure respects both intuitions mentioned at the beginning of this section. It thus resolves the puzzle of how sensory pleasure can be a kind of common feeling for which the heterogeneity of sensory phenomenology is not a problem.

\footnotetext{
${ }^{25}$ So there are no affectless sensory experiences. But some sensory experiences are affectively neutral they have a neutral affect, so to speak. Think of affective dimension as always present and as having a ratio scale with a neutral value somewhere in between the positive and negative ends.

${ }^{26}$ In our (2013), Matt Fulkerson and I argue for a largely Lockean dispositional account of affective qualities as qualifying the worldly objects of our affective experiences.

27 The analogy with dancing is only just that, of course — an analogy, intended to help understand how we can conceive of hedonic tone as adverbial/affective modification of sensory qualities. But it shows that there is nothing mysterious about the peculiar phenomenology of sensory affect — or at least, there needn't be any.
} 
But what does the adverbial modification of a sensation consist of, metaphysically speaking? What are the naturalistic underpinnings of this adverbialist model?

\section{Psychofunctionalism}

There is a prima facie plausibility to attitudinal views of sensory pleasure: in undergoing a pleasant sensation we are in a state that seems to have a certain kind of motivational tug or pull. We experience this pull as a kind of motivational bias, or even a pre-motoric oomph - some kind of felt urge. In short, some kind of desire-like state is involved somewhere in feeling a pleasant sensation. We have seen that the ordinary intuitive notion of desire, or indeed, of any pro-attitude like wanting or liking, isn't up to capturing this, especially when directed toward the sensation involved. The notion the attitudinal theorists seek is, intuitively, a functional role notion, ${ }^{28}$ only partially and superficially capturable in terms of ordinary conative notions. Let's introduce the term 'p-desire' to denote the state type with the psychofunctional role of processing the incoming sensory information in whatever ways that realize the pleasantness of sensations. ${ }^{29}$ What would this involve? Answering this question isn't an armchair affair, but a quick look at affective neuroscience suggests that this role consists of a complex processing of incoming sensory information that, among other things, ${ }^{30}$

- sets interruptible motivational parameters (motivational biasing — "more-of-this" or "less-of-this" or "stop-this" incoming stimulus);

- prepares the effector or psychomotor systems of the organism, providing actionpreparedness (motor biasing);

- provides appraisals of the incoming sensory information for its significance for the organism and for its potential for enhancing its behavioral repertoire (epistemic/bioevaluative biasing);

- influences future action preferences (through associative or cognitive learning, habituation, incentive sensitization, etc.) on the basis of present sensory stimuli's informational content and its immediate behavioral etiology;

- provides steady, earmarked input to more centralized concept-wielding cognitive, conative, and decision-theoretic systems.

\footnotetext{
${ }^{28}$ Actually, a psychofunctional role notion - see below. See Block (1980) for the distinction between functionalism and psychofunctionalism.

${ }^{29}$ See Aydede (2000), where p-desiring was called 'desiring*'. For a similar treatment of pain affect, see Clark (2005). The framework to be presented below was, in outline form, part of a paper co-written with Matt Fulkerson that was presented in the Pacific APA meetings in San Francisco, 2013, and in San Diego, 2014. We plan to continue collaborating on this topic. For a critical survey of theories of affect (pain affect, in particular) developed in contemporary philosophy of mind, see our joint work (forthcoming), and for a sustained criticism of strong representationalism about sensory affect (about pain), see our (2014).

${ }^{30}$ See Berridge (2004), Rolls (2005), Panksepp (1998) — among others.
} 
We can think of p-desiring as a complex modification (filtering, enhancing, biasing, amplifying, affording reinforcement, etc.) of the incoming sensory information that will causally influence, in the above ways, the subject's motivational, cognitive, and behavioral priorities in such a way that makes some of this available to the subject's conscious thoughts and conative attitudes. This may result, when appropriate or needed, in the subject's judging that she likes the taste or that she finds the taste pleasant, where judging is a conceptual affair epistemically based on her pleasant sensation, i.e., on her affectively modified perceptual experience. Let me give you an extended analogy that should help to convey the feel of the proposal or the general picture of how I intend this psychofunctionalist proposal to go.

Consider how a large-scale intelligence gathering operation might proceed for a government central security agency. It starts with access to information generators in the relevant channels such as internet activity, cell phone conversations, or drone surveillance. The ensuing processing will be interest-relative carried out against a huge set of background concerns and knowledge. If the operation is large scale, its initial stages need to be automatized to weed out irrelevant data before it reaches the higher decision making centres. So, the processing needs to establish a set of hierarchically organized filters, relevancy criteria, and priority handling procedures early on. For instance, complex algorithms are needed to prune the vast amount of initial data to a manageable set on the basis of potential relevancy criteria. This pruning may include looking for key words, search phrases, patterns of words/phrase structures, intonations, volume, geographical and temporal sources of the data, their combinations and repeating patterns, etc. Throughout this multi-stage processing we can imagine certain data being dropped while some others are retained and marked for further processing. These may be routed to different computational centers for extracting further information for their significance and relevance as well as levels of potential threat. As the information processing progresses, the amount of data to be processed will diminish, but these later stages will require more intelligence as they are closer to decision making stages. This requires more information integration from various different sources including past data, communication and coordination with other agencies, etc., as well as activation of further data gathering resources focused on a range of potential targets. These later stages will also involve mobilization of potential action units, readying plans and securing required resources and capacities, planning and preparing for the consequences of these action plans, comparing their results against a set of goals, and eventually somebody's pushing the button, say, to fire a Hellfire missile on a target. Often, by the time the decision is made, most of the contingencies and readiness for various actions must have (hopefully) already been planned and secured. Many times, all this processing and planning will result in no action, sometimes operations that are underway will be aborted - depending on what other priorities take precedence in light of further developing events here and there. Note that many, perhaps most, stages of this complex information processing can be done without 
higher decision making or central executive units being informed. I take it, most of the time, the director of the agency on the top floor doesn't need to know about the details or the history of a given operation underway controlled at the basement. Further, the President's Office across the river needs to be contacted and informed only when the level of significance of the developing events reaches a certain critical point. The information reaching the President's Office will be brief, devoid of unnecessary details with a format appropriate for the executive function of this Office to be integrated into the conscious central planning and execution of national affairs.

It is useful to think of the style of affective information processing involved in pdesiring as similar to this agency's processing of information to mark the significance of the incoming information, to prioritize and establish action plans accordingly, to ready their motor plans, coordinate their execution in light of developing events, and record the history of the operation and the ensuing results for future actions, and pass it over to higher central cognitive centres in charge of more reflective conduct of the organism as a whole. This is information processing for potential action and learning — it's inherently motivational.

P-desiring is for now largely a placeholder for whatever the scientific research will eventually reveal about the nature of this psychofunctional role. The claim here is that the metaphysics of sensory affect consists in a certain kind of causal processing or modification of incoming sensory information. P-desiring incoming sensory information is mostly a subpersonal process revealed in consciousness as a pleasant or unpleasant sensation. But its functional nature is not altogether hidden at the personal level. As we have seen, this is what makes attitudinal theories prima facie plausible. The pleasantness of the taste of a piece of watermelon consists literally in my being motivationally (motorically, epistemically, etc.) biased toward that very taste, and toward the watermelon for that matter, in the very experiencing of that taste. This is how that taste (and the watermelon) is being presented to my consciousness. The pleasantness, in this sense, is the "felt evaluation" of that taste. ${ }^{31}$

So, sensory pleasure - as the adverbial modification of the way a sensation is instantiated in experiential consciousness - metaphysically consists of p-desiring incoming sensory information at the subpersonal level where p-desiring is to be cashed out at the level of engineering design of autonomous agents that consume sensory information, i.e., psychofunctionally. Adverbialism offers a personal-level framework within which we can properly conceptualize affective phenomenology as adverbial/affective modification of sensory phenomenology. Psychofunctionalism then offers the naturalistic underpinnings of

\footnotetext{
${ }^{31}$ Terminology is borrowed from Helm (2002) - although his position differs from mine in significant ways. Here in this paragraph, it is actually helpful to leave 'taste' ambiguous between the taste sensation and its worldly object (say, molecules on your tongue). As discussed above, either will do in this context.
} 
how this modification is realized as a certain kind of functional role ( $\mathrm{p}$-desiring) at the (largely) subpersonal level. ${ }^{32}$ We can summarize the emerging picture thus:

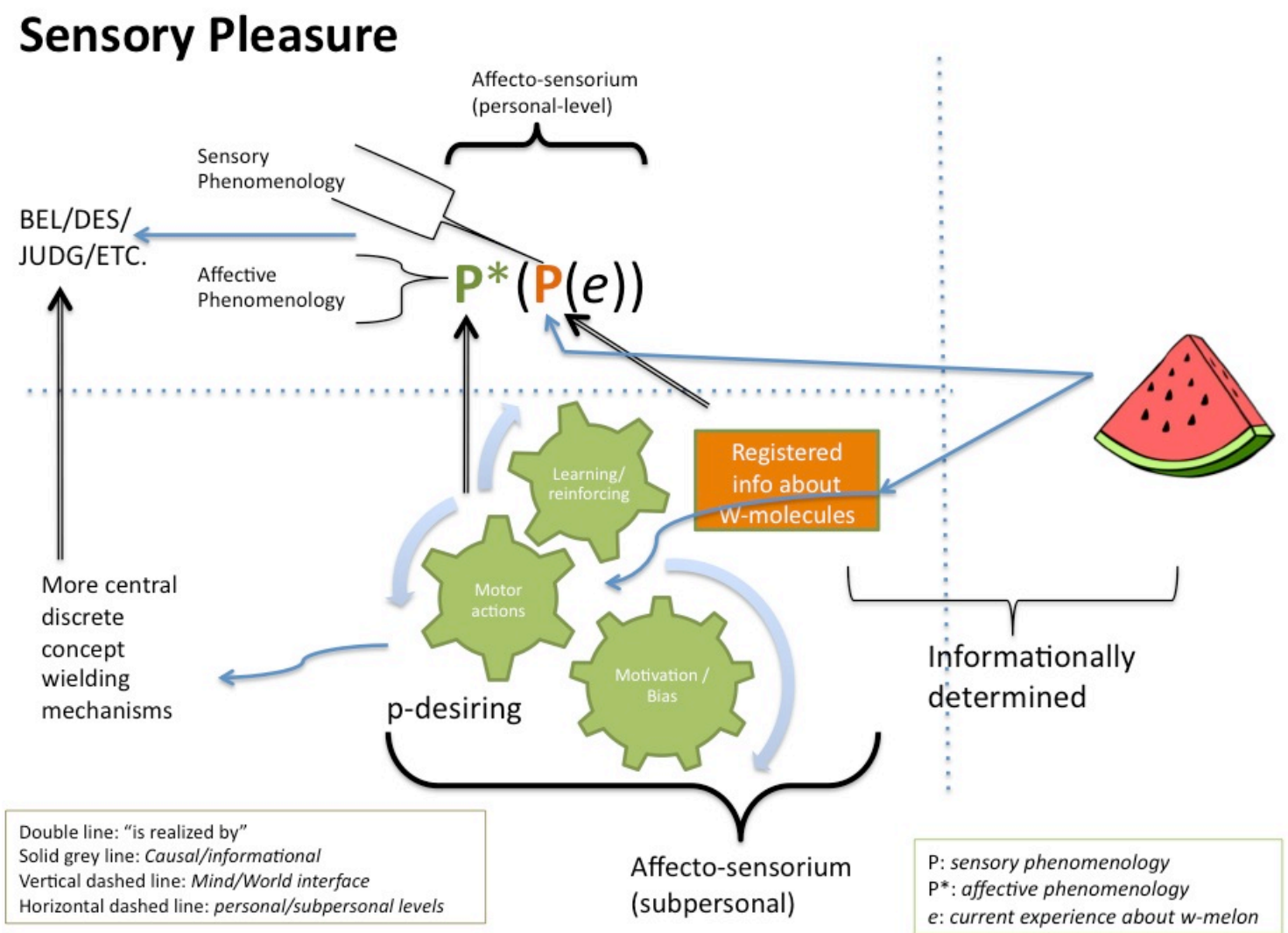

Figure: Metaphysical and phenomenological structure of sensory pleasure

\section{World-directed experiential (phenomenal) desire interpretation of sensory pleasure}

There is a long and venerable tradition in philosophy of mind that treats the phenomenology of perceptual experience as representational. There are different versions of this story with varying degrees of metaphysical or reductionist ambitions. Consider the (weak) representationalist claim that sensory phenomenology consists of non-conceptual (analog) representation of the complex physical sensible properties of objects we perceptually encounter in our environment. Indeed, very few would dispute the claim that sensory experiences carry information about certain range of physical properties or magnitudes of perceptible objects or events. If we add that this is in fact their proper function, it would be quite natural to treat sensory experiences as essentially

\footnotetext{
${ }^{32}$ I should note, however, that a property dualist about mental properties can easily accept the framework I am offering: just interpret the realization relations (indicated by double arrows in the Figure) as causal (or non-causal, for that matter) correlations between the instantiations of physical and mental properties.
} 
representational. The character of sensory representation would then be differentiated by their peculiar representational content, their format, and their functional role as an interface between the world and the more central concept wielding mechanisms. On this view, sensory representation would have accuracy conditions: they can be veridical or not, true or false. In the picture above, the predicate $P$ would nonconceptually (in analog form) represent certain physical features of the watermelon (call this $W$ ) . We may, for convenience, call this form of representation, phenomenal believing, or for short, $p$ believing (p-believing that $x$ is $W$ ). ${ }^{33}$ Ordinary perceptual beliefs, such as the belief that the watermelon is crisp and juicy, would be causally generated and, when appropriate, epistemically justified by the relevant perceptual experience ( $\mathrm{p}$-belief), or more precisely, by the relevant sensory phenomenological aspects of the experience - these aspects having an indicative function.

As pointed out above, pleasant sensations generally give rise to ordinary desires that we can express, for instance, linguistically. If I find the taste of watermelon pleasant on the basis of how it tastes affectively, ceteris paribus, I may form a desire to taste or continue tasting the watermelon as long as it tastes pleasant. What rationalizes and justifies this ordinary desire of mine is how the watermelon tastes to me affectively - how the taste sensation, and thus the watermelon, strikes me affectively in experiencing it. This is the pleasantness of the sensation. We have, then, a parallel relationship between the affective phenomenology of the taste experience, p-desiring (or, $P^{*}$ ), and the conceptually structured conative states formed on the basis of, and justified by, this affective phenomenology. ${ }^{34}$

On this way of looking at the picture, the pleasantness of a sensation is, crudely put, a satisfied experiential/phenomenal desire that is world-directed, just as the sensation involved is world-directed. If my taste sensation of the watermelon is pleasant, I am both p-believing and p-desiring (certain physical features of) the watermelon $(W)$, which together constitute my taste experience of it. The affective phenomenology is ontologically dependent on the sensory phenomenology involved in this experience - $\mathrm{p}$ desiring being the adverbial/functional modification of p-believing.

An advantage of this way of looking at sensory pleasure is that we seem to have a good explanation of why or how it could be intrinsically good. For the pleasantness $\left(P^{*}\right)$ of a sensation $(P)$ of a sensible property $W$, roughly, amounts to p-desiring the instantiation

\footnotetext{
${ }^{33}$ Compare Byrne's exing that $P$ (2009), roughly experiential "believing" that $P$ that feeds normally into the mechanisms of ordinary perceptual belief formation. Here the referential position indicated by ' $x$ ' would be transparent and de re. The choice of the word 'phenomenal believing' isn't entirely happy but the emphasis is on the perceptual experiences' assertoric force in reporting how one's immediate physical environment is like in modality specific ways.

${ }^{34}$ See my (2000: 559-60) for an earlier version of this, at bottom functionalist, story where I called pdesiring the incoming sensory information, desiring*, and equated it with the sensory pleasure associated with sensing the world through our sensory modalities. This was an attempt to agree with Ryle's naturalism (as against the excessive mentalism of his opponents) while still insisting that sensory pleasure is not merely a dispositional affair, but a phenomenological occurrence in one's consciousness.
} 
of $W$ while p-believing it - that is, it amounts to having one's p-desires being satisfied as registered by the relevant $\mathrm{p}$-beliefs. Depending on the design features of the system, we may even say, roughly, that sensory pleasure amounts to having $\mathrm{p}$-desires $\mathrm{p}$-believed to be satisfied. ${ }^{35}$ It seems intuitively obvious that if any psychological fact is intrinsically good, experiential registration of the satisfaction of one's desires is intrinsically good.

So suppose I taste this piece of watermelon. I find the taste pleasant: I am having a pleasant sensation. On the present proposal, I am p-believing that a certain complex sensible property $(W)$ is being instantiated on my tongue, where the whole that-clause is to be read transparently but in the format of the relevant sensory code $(P)$ : whatever it is that is causally responsible for the distinctive watermelon taste I am having, that is $W$ ( $W$ being instantiated on my tongue). I am also simultaneously p-desiring $\left(P^{*}\right)$ that this $W$ be occurring. This is the affective-sensory experience and its phenomenology.

But, being reflective, I may also form the ordinary perceptual belief that that is $W$, and the ordinary desire that I taste this $W$, which I can express linguistically by saying, for instance, that this is good watermelon, or that this watermelon tastes pleasant, or that I want this watermelon, etc. But also, being really reflective, I may additionally form the introspective belief that this watermelon tastes like that, where the latter demonstrative refers to the characteristic way the watermelon tastes to me - its distinctive phenomenal character. As well, I may form the introspective desire that I continue having this sensation. Thus, my pleasant taste sensation may generate and justify two ordinary desires: one is world-directed and the other experience-directed. The ordinary world-directed desire is epistemically justified by the fact that I p-desire the watermelon, and the ordinary experience-directed desire is normatively justified by the fact that the pleasant sensation I am having is intrinsically good $(\approx$ I am having a p-desire I am p-believing to be satisfied), and I can grasp it as such.

If sensory pleasure is a form of world-directed satisfied desire (an experiential or phenomenal desire of, say, sensible property $W$ in the very act of sensing $W$ ), then we have a fairly straightforward account of the motivating and justifying power of sensory pleasure as a kind of feeling realized psychofunctionally (roughly, as p-desiring $W$ while sensing $W$ ). Moreover, the puzzle about opposite valences finds a good solution if we note that we

\footnotetext{
${ }^{35}$ The qualification "roughly" is required because the description in terms of p-desires and p-beliefs is close to personal level descriptions and may not neatly correspond to any natural delineation of affective mechanisms constituting p-desiring. For instance, it may not be strictly correct to say that sensory pleasure is a p-desire p-believed to be satisfied, since what is p-believed is that, say, a certain taste objectively understood $(W)$ is present in my mouth as a result of biting into a watermelon (indicative sensory phenomenology), but this is also what is p-desired (affective/conative phenomenology). There may be further mechanisms in the affective/sensory mechanisms that may additionally register the fact that what is $p$ believed satisfies what is thus p-desired. Whether this is so depends on further empirical facts about how affective systems work as a network between informational, motivational (drive), and learning mechanisms. The consciously registered sensory pleasure may arise out of an engineering need to have an explicit signal for desire satisfaction: an autonomous system capable of individual reinforcement learning needs to know when and how its desires or p-desires are satisfied or frustrated as a consequence of its own actions.
} 
can have experiential aversions - p-aversions, as it were, psychofunctionally understood in ways analogous to p-desires. The unpleasantness or painfulness of pains, or indeed, of many sensations, can then be understood, at the personal level, as adverbial modifications of incoming sensory information realized, at the subpersonal level, as certain psychofunctional roles. $^{36}$

\section{Conclusion}

I have described my account as having three levels: an adverbialist and a psychofunctionalist level, and a level in between at which we can describe sensory pleasure as (satisfied) experiential desire. Adverbialism is meant to provide a model for understanding the elusive and puzzling phenomenology of sensory pleasure (and sensory affect in general). This is fully at the personal level. I invite you to pay close attention to your own sensory affective phenomenology, based on lived experiences, and see whether my proposal makes better sense than my rivals'. Accurate phenomenological observations are hard to make, and disagreements about how the phenomenology of certain kinds of experiences is structured are particularly difficult to settle. But my primary argument for adverbialism is its intuitive explanatory and unifying power: it makes sensory pleasure a phenomenal episode (a kind of feeling) without falling prey to the heterogeneity problem that plagues all felt-quality views. I believe, it makes better sense of what hedonic tone theorists have had in mind all along when they claimed that the pleasantness of a sensation is an affective "toning" of the relevant sensation. It also captures the truth in the attitudinal theories by taking sensory affect to modify (or, apply to) sensations. The metaphysical essence of this modification is functional: sensations carry information for autonomous intentional organisms that use it for their various aims (consciously or unconsciously). The affect of a sensation is a way of marking the teleological significance of that sensation, and

\footnotetext{
${ }^{36}$ Additionally, the present proposal seems to provide a potential resolution of certain core aspects of the debate between (normative) reason internalism and reason externalism. Suppose we have naturalistically secured the notion of experiential desire and belief - as indicative and conative/desiderative representation in sensory code (as sensory information being p-desired). Then just as sensory/perceptual experiences can justify our perceptual beliefs, experiential desires (p-desires) can rationalize and justify our ordinary desires as conceptually structured propositional attitudes (o-desires). Reason externalism could be defended only as applied to o-desires - all ordinary desires do or can admit non-arbitrary reasons. For instance, the reason for $\mathrm{o}$-desiring to get rid of pains is that pains are intrinsically bad (continually frustrated p-desires). The reason for o-desiring pleasant sensations is that they are intrinsically good. But then there wouldn't be any reason internalism as applied to p-desires - p-desires aren't the kind of states that can have reasons (unless they are perceptions of objective sensuous value à la Johnston, 2001, in which case they would become p-beliefs about objective sensuous value). Reason externalism would thus win the debate but the insights of reason internalists would nevertheless be preserved - assuming that sensory desiderative phenomenology is not the registration of objective value beyond one's skin (à la Johnston). We can also objectively explain the existence of p-desires perhaps depending on various evolutionary selective pressures. We have, in other words, a whole new conceptual space within which many other problems in the vicinity could be fruitfully explored and possibly resolved.
} 
thus, of what that sensation represents, for the organism. There is something essentially desire-like in a pleasant sensation.

The psychofunctionalist proposal is meant to cash out the naturalistic underpinnings of this adverbial modification of sensations. I have introduced the term 'p-desire' to stand for whatever complex psychofunctional role realizes the affective modification of incoming sensory information. The essence of this role is to get the organism "move" or prepare for moving - it is inherently motivational. The choice of 'desire' in this quasitechnical term ' $p$-desire' is not accidental: when you look at the various aspects of this role in detail (as crudely illustrated above), it becomes conceptually compelling to treat the role as conative and motivational. But this is the role of affect that makes sense only in the context of processing the incoming sensory information about the world, in other words, only in the context of cognition (broadly speaking) of the world with which we are perceptually in contact and in which we act.

However, as the attentive reader might have noticed, I have also occasionally used the term 'p-desire' above deliberately to describe something that makes phenomenological sense in the light of what is said at these two levels: to describe sensory pleasure as a (satisfied) world-directed experiential desire in phenomenal form. When I am tasting the watermelon in my mouth, the sensory pleasure I experience draws me to the watermelon. Although it is my taste sensation that is primarily pleasant, this pleasantness as a phenomenal episode is an experiential desiring of the watermelon in the very act of tasting/sensing it - this is what p-desiring reduces pleasantness to. ${ }^{37}$ Thus, we can see

\footnotetext{
${ }^{37}$ In the contemporary philosophy of mind literature, representationalism about pain (the view that pain experiences nonconceptually represent some sort of physical disturbance in bodily locations) sometimes comes with a representationalist account of the painfulness or unpleasantness of pain that says that it consists of pain experiences' nonconceptually representing this disturbance as bad. This view could be extended to cover sensory pleasure as positive affect attaching to various sensations. On this view, the pleasantness of a sensory experience $e$ of sensible property $W$ consists of $e$ 's nonconceptually representing $W$ as good for the experiencer. And sometimes pain theorists do indeed mention that their theory can be extended this way. David Bain (2013), in particular, called his account of the negative affect of pain, evaluativism, and included Tye (2005), Cutter \& Tye (2011), and Helm (2002) as defending this broad view. I have criticized representationalism and evaluativism elsewhere - see my (2009) and Aydede \& Fulkerson (2014, forthcoming). Here let me briefly point out that there is a trivial sense in which my experiential-desire account of sensory pleasure might be seen to belong to this category of views too if we (plausibly enough) stipulate that p-desiring $W$ (i.e. experientially desiring $W$ ) is representing $W$ as good. Or better: necessarily, organism $O$ experientially desires $W$ if, and only if, $O$ experientially represents $W$ as good for $O$. This is meant to give the accuracy conditions for $O$ 's representing $W$ as good: the representation is accurate (i.e., $W$ is good for $O$ ) if, and only if, $O$ experientially desires $W$. I am prepared to grant that there is an intuitive (indeed, almost stipulative) sense in which what it is for something to be good for one is simply for one to desire it. But evaluativists have a more robust, substantive, and less subject-dependent notion of goodness or badness in mind (such as bodily badness, aptness to harm, etc.) when they propose their accounts as philosophically illuminating substantial theories (indeed sometimes as reductive theories) - this is why they worry about how to naturalize the psychosemantics involved in representing something as good or bad, or about the so-called messenger-shooting objection (why should representing something as bad itself be bad?) - see Jacobson (2013) for a more recent and detailed articulation of this last objection. The trouble with this way of looking at my view is that it is only "representationalist" by courtesy, as it were, since if p-desiring $W$ is what makes $W$ good then representing $W$ as good cannot be mistaken. But then what is the wisdom of
} 
how the pleasantness of a sensation is inherently motivational and can play a justificatory role in the formation of ordinary beliefs and desires. The attitudinal theorists were right in insisting that there is a conative attitude involved in sensory pleasure, but they got the intentional object of this conative attitude wrong. Clearly, when I have a pleasant sensation $S$ of a sensible (physical) property $W$, I generally desire, want, or like $S$. But this is not what constitutes the pleasantness of the sensation. What is constitutive is the fact that my p-desiring $W$ is being satisfied as registered by my sensing $W$ - revealed phenomenologically as $S$ being affectively/adverbially "toned" (modified). Thus the present view is a form of desire-satisfaction account of what constitutes the intrinsic goodness of sensory pleasure.

I wish I had a catchier and descriptively more revealing name for my three-level account of pleasure. But good and comprehensive theories are hard to nail down by single descriptive names: thus, my adverbialist, functionalist, and experiential-desire view of sensory pleasure (indeed, sensory affect in general) is one view describing the same phenomenon at three different levels. ${ }^{38}$

\section{References}

Armstrong, D. M. 1962. Bodily Sensations. London, Routledge and Kegan Paul.

Alston, W. 1968. "Pleasure.” In The encyclopedia of philosophy, edited by P. Edwards. New York: Collier-Macmillan.

Aydede, M. 2000. “An Analysis of Pleasure Vis-à-Vis Pain.” Philosophy and Phenomenological Research 61(3): 537-570.

Aydede, M. 2009. "Is Feeling Pain the Perception of Something?” Journal of Philosophy 106(10): 531-67.

Aydede, M. 2014. "How to Unify Theories of Sensory Pleasure: An Adverbialist Proposal." Review of Philosophy and Psychology 5(1): 119-33.

Aydede, M. Forthcoming. "Is the Experience of Pain Transparent? Introspecting Phenomenal Qualities.”

Aydede, M. \& Fulkerson, M. 2013. “Affective Qualities.” Presentation at the Pacific APA meeting in San Francisco, April 3013.

classifying it as representationalist or as a version of content view? My view is friendly to intentionalism about experience - indeed it is a form of weak representationalism. But the experiential-desire view of affect is functionalist at its metaphysical core defined over information carrying states.

${ }^{38}$ Many thanks to Matt Fulkerson, Dom Lopes, and Lisa Shapiro for their useful comments. Special thanks to Lisa Shapiro for inviting me to participate in this project and the fantastic conference that preceded this volume. 
Aydede, M., \& M. Fulkerson. 2014. “Affect: Representationalists' Headache.” Philosophical Studies 170: 175-98.

Aydede, M., \& M. Fulkerson. Forthcoming. "Reasons and Theories of Sensory Affect." Forthcoming in The Nature of Pain, edited by David Bain, Michael Brady and Jennifer Corns. (An early version was presented at the Pacific APA meeting in San Diego, 2014).

Aydede, M., \& Güzeldere, G. 2005. "Cognitive Architecture, Concepts, and Introspection: An Information-Theoretic Solution to the Problem of Phenomenal Consciousness." Noûs, 39(2): 197-255.

Bain, D. 2013. “What Makes Pains Unpleasant?” Philosophical Studies 166(1): 60-89.

Berridge, K. 2004. "Motivation concepts in behavioral neuroscience.” Physiology \& Behavior 81(2): 179-209.

Block, N. 1980. “Troubles with functionalism.” In Readings in philosophy of psychology Vol. 1, edited by Ned Block, 268-305. Cambridge, MA: Harvard University Press.

Brady, M. 2013. "Pain and the Euthyphro Dilemma." Paper presented at the Pain Conference, University of Glasgow, June 18-20, 2013.

Bramble, B. 2011. "The distinctive feeling theory of pleasure. "” Philosophical Studies, 162(2): 201-217.

Brandt, R. 1979. A Theory of the Good and the Right. Oxford: Clarendon Press.

Brink, D. 1989. Moral Realism and the Foundations of Ethics. Cambridge: Cambridge University Press.

Broad, C. D. 1930. Five Types of Ethical Theory. London: Routledge and Kegan Paul.

Byrne, A. 2009. "Experience and content.” The Philosophical Quarterly 59(236), 429-451.

Clark, A. 1996. Sensory Qualities. Oxford University Press.

Clark, A. 2005. "Painfulness is Not a Quale." In Pain: New Essays on Its Nature and the Methodology of Its Study, edited by M. Aydede, 177-198. Cambridge, Mass.: MIT Press.

Crisp, R. 2006. Reasons and the Good. Oxford University Press.

Cutter, B., \& Tye, M. 2011. "Tracking Representationalism and the Painfulness of Pain.” Philosophical Issues 21(1): 90-109.

Davis, W. A. 1981. "Pleasure and happiness.” Philosophical Studies 39(3): 305-317.

Davis, W. A. 1982. “A Causal Theory of Enjoyment.” Mind 91(362): 240-256. 
Duncker, K. 1941. “On Pleasure, Emotion, and Striving.” Philosophy and Phenomenological Research 1(4): 391-430.

Feldman, F. 1997. “On the Intrinsic Value of Pleasures.” Ethics 107: 448-466.

Feldman, F. 2001. "Hedonism.” In The Encyclopedia of Ethics, edited by L. C. Becker, \& C. B. Becker, 662-669. New York: Routledge.

Feldman, F. 2004. Pleasure and the Good Life. New York: Oxford University Press.

Findlay, J. N. 1961. Values and Intentions. London: Allen \& Unwin.

Hall, R. 1989. “Are Pains Necessarily Unpleasant?” Philosophy and Phenomenological Research 49(4): 643-659.

Heathwood, C. 2006. "Desire Satisfactionism and Hedonism.” Philosophical Studies 128(3): 539-563.

Heathwood, C. 2007. "The reduction of sensory pleasure to desire.” Philosophical Studies 133: $23-44$.

Heathwood, C. 2011. "Desire-based theories of reasons, pleasure, and welfare." Oxford Studies in Metaethics 6: 79-106.

Helm, B. 2002. "Felt evaluations: A theory of pleasure and pain." American Philosophical Quarterly 39(1): 13-30.

Goldstein, I. 1980. "Why People Prefer Pleasure to Pain.” Philosophy 55(213): 349-362.

Jacobson, H. 2013. "Killing the Messenger: Representationalism and the Painfulness of Pain.” The Philosophical Quarterly 63(252): 509-519.

Johnston, M. 2001. "The Authority of Affect." Philosophy and Phenomenological Research 63(1): 181-214.

Katz, Leonard D. 1986. Hedonism as Metaphysics and Value. Ph.D. Dissertation, Princeton University.

Katz, Leonard D. 2006. "Pleasure." In The Stanford Encyclopedia of Philosophy (Spring 2014 Edition), edited by Edward N. Zalta. URL = $<$ http://plato.stanford.edu/archives/spr2014/entries/pleasure/>.

Kahane, G. 2009. "Pain, Dislike and Experience.” Utilitas 21(3): 327-336.

Kagan, S. 1992. “The limits of well-being.” Social Philosophy and Policy 9: 169-189.

Klein, C. Forthcoming. "What Pain Asymbolia Really Shows." Mind.

Labukt, I. 2012. "Hedonic Tone and the Heterogeneity of Pleasure." Utilitas 24(02): 172199. 
Levine, J. 1983. "Materialism and qualia: The explanatory gap.” Pacific Philosophical Quarterly 64: 354-361.

Levine, J. 1993. “On Leaving Out What It's Like.” In Consciousness, edited by Martin Davis and Glyn W. Humphreys. Oxford, UK: Basil Blackwell.

Martínez, M. 2011. "Imperative content and the painfulness of pain.” Phenomenology and the Cognitive Sciences 10(1): 67-90.

Moore, G. E. 1903/1993. Principia Ethica. In T. Baldwin (Ed.). Cambridge: Cambridge University Press.

O'sullivan, B., \& Schroer, R. 2012. "Painful Reasons: Representationalism as a Theory of Pain.” The Philosophical Quarterly, 62(249): 737-758.

Panksepp, J. 1998. Affective Neuroscience. New York: Oxford University Press.

Parfit, D. 2011. On What Matters. Vol. 1. Oxford University Press.

Pitcher, G. 1970. "Pain Perception." Philosophical Review 79(3): 368-393.

Robinson, W. S. 2006. "What Is it Like to Like?” Philosophical Psychology 19(6): 743765.

Rolls, E. T. 2005. Emotion Explained. Oxford University Press.

Ryle, G. 1954. "Pleasure.” Proceedings of the Aristotelian Society (Supp.) 28: 135-146.

Sidgwick, H. 1907/1981. The Methods of Ethics. 7th Ed. Macmillan.

Schroeder, T. 2001. "Pleasure, displeasure, and representation." Canadian Journal of Philosophy 31(4): 507-530.

Schroeder, T. 2004. Three Faces of Desire. Oxford University Press.

Sprigge, T. L. S. 2000. "Is the esse of intrinsic value percipi?: pleasure, pain and value." Royal Institute of Philosophy (Supp. Volume) 47: 119-140.

Smuts, A. 2011. "The feels good theory of pleasure.” Philosophical Studies 155(2): 241265.

Tye, M. 1995. Ten Problems of Consciousness: A representational theory of the phenomenal mind. Cambridge: MIT Press.

Tye, M. 2005. “Another Look at Representationalism about Pain.” In Pain: New Essays on Its Nature and the Methodology of Its Study, edited by M. Aydede. Cambridge, Mass.: MIT Press.

Wolfsdorf, D. 2013. Pleasure in Ancient Greek Philosophy. Cambridge: Cambridge University Press. 